\title{
The Degree of Symmetrical among the Teaching Staff at Tafila Technical University
}

\author{
Hani Kraimeen ${ }^{1} \&$ Suleiman Al - Hajaya ${ }^{1, *}$ \\ ${ }^{1}$ Faculty of Educational Sciences, Tafila Technical University, Tafial, Jordan \\ *Correspondence: Faculty of Educational Sciences, Tafila Technical University, Tafial, Jordan. E-mail: \\ suhajaya@ttu.edu.jo
}

Received: August 8, 2017

Accepted: August 20, $2017 \quad$ Online Published: August 23, 2017

doi:10.5430/wje.v7n4p93

URL: https://doi.org/10.5430/wje.v7n4p93

\begin{abstract}
The study was conducted to identify the degree of symmetrical among the teaching staff members at Tafila Technical University. The study community was comprised of all the 239 members of the teaching staff at Tafila Technical University. The study sample was selected by using the stratified random method according to the faculty variable which included 132 members of the teaching staff. In order to achieve the study objectives; a questionnaire was prepared. Whereas, the study results showed that the degree of identification among the members of the teaching staff was moderate. In addition, the members of the teaching staff at the rank of associate professor and above in the humanitarian faculties have obtained the highest averages on identification dimensions of the tool (loyalty, identification, membership).
\end{abstract}

Keywords: symmetrical; educational administration; Jordanian universities

\section{Introduction}

The consistency between the objectives of individuals and the objectives of the organizations is an essential requirement for efficiency and effectiveness in institutions, where the individuals become part of the vision of the institution and its objectives. This consistency in the objectives contributes to the emergence of positive feelings towards work and achievement, which makes the workers more involved in the work. This will lead to a state of identification on the basis of sharing the same goals. The symmetrical increases the employees' loyalty to their institution and establishes a strong relationship between the institution and workers.

The symmetrical is a renewed form of social identification that strives to bind employees to the vision and mission of the institution and to their strong attachment to their values and their desire to remain and continue to serve it (Hant \& Morgart, 1994). Symmetrical refers to reshaping the self-concepts of employees to conform to the concepts and values of the organization (Mael \& Ashforth, 2001). Dutton believes that the symmetrical is the degree to which members define themselves through characteristics that they think distinguish the organization (Al Bashabshah, 2006).

Johnson, Johnon, and Heimberg (1999) define it as a process of internal and external persuasion through the desires of the individual that go in line with the wishes of the organization. Which results in a state of identification on the basis of the adaptation of these desires. Caro (2001 as cited in Al Shawawrah, 2006) sees it as similarity between the values and objectives shared by individuals and the organization.

Identification has positive effects in job performance, coordination between the departments, affiliation to the organization, outstanding achievement, the implementation of tasks with less time and effort and it increases the motivation and enthusiasm towards creativity and innovation and the development of their values (Al Saud, Sarayra, $\&$ Khalid, 2009). The individual can make a change or develop a value by overcoming points of disagreement or difference. When compared with other competitive organizations, we can say that the identification increases the degree of loyalty and activates cooperation. It also means to put the public interest before the private when providing alternatives and decision-making. Identification helps the workers in achieving job satisfaction which enhances the spirit of one team among the workers to reflect the bright and effective image of the organization (Rachid, 2003). 
There are a number of factors that help in the development of symmetrical including satisfying the needs of workers, so that the institution becomes a place to feel stable. In addition to adopting the policies that help to satisfy their needs in order to generate a sense of satisfaction and confidence (Lozi, 2006) and show their social status in the organization to reflect positively on the good performance and increase productivity (Sarayra, 2005), and other factors that include clarity of the objectives, thus the more the objectives are clear the more they will be achieved. This will enhance symmetrical loyalty and belonging to the organization (Lozi, 2006). The incentives are important in urging individuals to complete the work and satisfy their needs and build symmetrical confidence which means the compatibility of the expectations of individuals and the harmony of their behavior in order to achieve their common interests and bring them to the normalization stage In which individuals acquire values, attitudes, standards and patterns of behavior that are consistent with the interests of the organization (Al Hathlol, 2008). Moreover, the symmetrical identifies the problem of social identity at work and enhances the attractiveness of symmetrical and constitutes a good model for the work group (Al Qarala, 2011).

The main task of the tool is scientific and educational before being administrative, so it must be aware of most of the tools of the leaders and their activities and attitudes and characteristics and methods of selection and the extent of their awareness of their educational artistic role and knowledge of the needs of their students. Because it is simply possible to determine the level of symmetrical identification in educational institutions by determining the level of the relationship between the members of the faculty and management and by determining the level of awareness of the members of the importance of their role in the success of the institution in the performance of its duties and the individuals' sense of loyalty and belonging and the desire to maintain the status of the institution and reputation (Al Qarala, 2005)

The importance of symmetrical in both theoretical and practical aspects is linked to the organization's influence and strength. The work of the society is achieved through the organizations and the role of management is urging the institutions to carry out these tasks and to create the conditions, environment and climate in order to achieve and develop the model of the concept of performance, in addition to the expected reactions to performance and the use of reinforcement and feedback to achieve control and attention (Nader \& Tushman, 1980).

\subsection{The Study Problem}

It can be said that the efficiency and effectiveness of educational institutions and their ability to achieve their goals emanate from the harmony of the objectives of the institutions with the objectives of their employees, which contributes to the completion of tasks and duties in a distinctive way and provides a kind of positive psychological and emotional relationship between the institution and employees and enforces their sense of loyalty and commitment and increases job satisfaction and motivation for work and the desire to carry out difficult tasks and bear the consequences of decisions and responsibilities in different situations. Based on this fact and as a result of the work in the field of education, the researchers faced a problem which deserves to be examined. The problem is how to identify the degree of symmetrical among the faculty members at Tafila Technical University by answering the following questions:

1. What is the degree of symmetrical among the faculty members of Tafila Technical University from their point of view?

2. Are there significant differences at the level of significance $(0.05=\alpha)$ in the degree of symmetrical among faculty members at Tafila Technical University from their point of view attributed to the variables of the faculty and academic level?

\subsection{Purpose of the Study}

This study aims to identify the concept of symmetrical and analyze its impact on the efficiency and effectiveness and the educational institutions achievement of its objectives. In addition to recommendations that help the decision-makers in the university to adopt this concept.

\subsection{Importance of the Study}

The following categories can benefit from the results of this research:

- Officials and decision makers in the Ministry of Education.

- Administrative officials at the university.

- Educational officials in the private sector.

- The bodies involved in the planning of higher education. 
- Faculty members in universities.

- Centers for the development of the performance of faculty members in universities.

\subsection{Procedural Terms of the Study}

Symmetrical: It is the individual's feeling of belonging to the institution in which he/she works and the development of social and emotional ties with the university, the faculty and the department in which he/she works measured by the total scores obtained by the respondent to identify symmetrical.

\subsection{Previous Studies}

Al Saud, Sarayra, and Khalid (2009) conducted a study entitled symmetrical among the teaching staffs in Jordan public universities and its relation to their job performance. The study aimed to identify the degree of symmetrical among the members of the teaching staff in the public Jordanian universities and to indicate its relation to their job performance. The study community comprised all the full time members of the teaching staff, about (2905) and the heads of the academic departments, about (314). The results showed that the degree of symmetrical among members of the teaching staff was high and that their performance from the point of view of the heads of their departments was high. The results showed a statistically significant relationship between symmetrical and job performance.

Al Shawawrah (2015) conducted a study aimed to identify the degree of symmetrical among the teachers of the Ministry of Education in the Directorate of Education of Karak borough and to indicate its relation to motivation. A sample composed of (104) individual was selected and the results showed that the degree of symmetrical among the teachers was moderate as well as their motivation to work. A statistically significant relationship was found between the symmetrical and the motivation.

Al Qarala (2005) conducted a study aimed at identifying the effect of the desired and perceived participation in the crystallization of the symmetrical among the faculty members in the public Jordanian universities. The results showed that the perceived participation was medium and the desired was high and that faculty members' perception about symmetrical was high and reflected a relation between the desired participation and the perceived participation at the level of the department and the faculty in the crystallization of symmetrical.

Jeffrey (2002) conducted a study aimed at determining the effect of symmetrical on the decision-making process and the role of the workers in this process. The study concluded that there is a statistically significant impact on symmetrical and decision making process.

Kinppenberg and Schie (2000) also conducted an analytical study aimed at analyzing the relationship between team work, social identification and the value of the organization, job satisfaction, and non- absence, harmony at work, motivation and enthusiasm. The results of the study showed that there is no statistically significant relationship between symmetrical on the one hand and between job satisfaction and non-absence on the other hand, and the existence of a weak relationship between symmetrical on the one hand, and job satisfaction, non-absence, hard working, and motivation on the other hand.

In order to determine the effect of procedural and distributive justice on symmetrical, Cremer (2005) conducted a study aimed at identifying the effect of procedural and distributive justice in symmetrical. A tool was used to measure procedural and distributional justice and the desire to cooperate and employees' awareness of identification. The study sample consisted of 142 researches from major industrial organizations in France. The results of the study showed that the interaction between procedural and distributional justice was only among workers who had an awareness of symmetrical.

Chan (2006) conducted a study aimed at identifying the level of symmetrical and level of loyalty among workers in an organization that serves humanitarian work in Malaysia. The study sample consisted of 96 respondents from the organization's staff. The results showed that the workers have symmetrical and high loyalty.

Al-Shammari (2012) conducted a study entitled: The degree of practicing leadership roles among the deans of the faculties of Kuwait University and its relation to the symmetrical among the faculty members from their point of view. This study aimed at analyzing and measuring the degree of practicing the leadership roles among the deans of the faculties of Kuwait University, measuring it and showing its relation to symmetrical among the teaching staff and from their point of view. The study sample included (400) faculty members, the results showed a statistically significant positive correlation at the significance level $(\alpha=0.05)$ between the democratic pattern and the symmetrical in Kuwait university. The results also showed positive correlative relation between the autocratic pattern and the symmetrical, statistically significant but very weak and there is no relationship between the lenient pattern and symmetrical. 
In sum, some of the previous studies dealt with the symmetrical and its relation to a number of variables: performance, motivation, desired and perceived participation, decision-making process, and work through team, procedural and distributional justice. Hence, previous studies did not address the level of symmetrical among faculty members in universities. This study is intended to give a clear idea in a public university.

\section{Methodology}

The following is a description of the study population and a distribution of the sample in light of the variables of the study (faculty and academic level). The study tool was also described and applied procedures, and how to evaluate the validity and stability of the study tool, as well as a description of the statistical treatments that were followed to answer the study questions.

\subsection{Study Approach}

In this study, the descriptive survey was adopted due to its relevance to the nature of the study and its objectives.

\subsection{Study Population}

The target population of the study is comprised all faculty members of Tafila Technical University; (239) member. Table (1) shows the distribution of the members of the study community, according to the variables of the study (faculty, academic level).

Table 1. Distribution of the Members of the Study Population by Variables of the Faculty and Academic Level

\begin{tabular}{lllll}
\hline & Scientific & Humanitarian & Total & Percentage \\
\hline Associate professor and above & 54 & 34 & 88 & $37 \%$ \\
Assistant professor and below & 99 & 52 & 151 & $63 \%$ \\
Total & 153 & 86 & 239 & \\
Percentage & $64.02 \%$ & $35.98 \%$ & & \\
\hline
\end{tabular}

Table (1) shows that the faculty members in the scientific faculties constitute the vast majority of the study population. They numbered (153) faculty members with a percentage of (64.02\%), while the faculty members in the humanitarian faculties constituted $35.98 \%$ of the study community as they reached (86) members. The faculty members at the level of associate professor and above reached (88) members and accounted for (37\%) of the study population. The number of faculty members at the level of assistant professor and below was (151) members, representing $63 \%$ of the study population.

\subsection{The Study Sample}

The sample of the study was chosen according to the random stratified method according to the faculty variable. It consisted of (132) faculty members, who constituted (55\%) of the study community. After the deletion of (7) questionnaires due to non-return or lack of validity for analysis, the sample reached (125) faculty members constituted (52\%) of the study community. Table (2) shows the distribution of the study sample by the variables of the study (faculty and academic level). Table (2) Distribution of the sample of the study according to the variables of the faculty and the academic level.

Table 2. Distribution of the members of the Study Community by Variables of the Faculty and Academic Level

\begin{tabular}{lllll}
\hline & Scientific & Humanitarian & Total & Percentage \\
\hline Associate professor and above & 21 & 16 & 37 & $30 \%$ \\
Assistant professor and below & 59 & 29 & 88 & $70 \%$ \\
Total & 80 & 45 & 125 & \\
Percentage & $64 \%$ & $36 \%$ & & \\
\hline
\end{tabular}

Table (2) shows the distribution of the sample members according to the variables of the study (the faculty and the academic level). The table shows that the number of faculty members selected from scientific faculties reached (80) faculty members and from humanitarian faculties reached (45) with respective percentages $(64 \%, 36 \%)$. The total number of faculty members at the level of associate professor and above was (37) with a percentage of (30\%) of the sample of the study, while the number of faculty members at the level of assistant professor and below reached (88) and by $(70 \%)$ of the study sample. 


\subsection{Study Tool}

The researcher prepared a questionnaire by studying the theoretical literature and previous studies on the subject of the study then the tool was built. In its initial form, it consisted of (3) areas and (19) items. After the presentation of the tool to the arbitrators, the final version of the tool consisted of (19) items distributed into three areas: the area of loyalty (7) items, and the area of identification (6) items, and the area of membership (6) items, validity and reliability was verified as follows:

\subsection{Validity of the Study Tool}

The validity of the study tool was verified by presenting it to (8) arbitrators specialists in the subject of study in the Jordanian universities from the members of the teaching staff in the specialties of the educational administration, measurement and evaluation. Their opinions, suggestions and amendments were adopted. The items agreed upon by more than (80\%) of the arbitrators were kept, and (3) items has been amended, and no item has been deleted or added, and thus the number of items of the tool has reached (19) items. According to the fivefold Likert- scale: very high degree, high degree, medium degree, low degree and very low degree.

\subsection{Reliability_of the Study Tool}

The degree of reliability of the tool was evaluated in an internal consistency method (Cronbach Alpha). The tool was applied to exploratory sample from outside the study sample, consisted of (22) faculty members, randomly selected. The data were then entered into the computer memory and the Cronbach Alpha coefficient was extracted. Table (3) shows the reliability results by area of study tool.

Table 3. The Value of the Reliability Coefficient of the Internal Consistency of the Tool As a Whole and for Each Area of Study

\begin{tabular}{ll}
\hline Area & Reliability Coefficient Value (Cronbach Alpha) \\
\hline Loyalty & 0.95 \\
Similarities & 0.92 \\
Membership & 0.89 \\
The tool as a whole & 0.96 \\
\hline
\end{tabular}

Table (3) shows that the study tool has acceptable reliability degrees for the purposes of this study. The reliability coefficient of the tool as a whole was (0.96), while the reliability coefficients for tool areas ranged from (0.89-0.95).

\subsection{Procedures for Applying the Study}

The study steps were implemented as follows:

- After reading the theoretical literature and previous studies on the subject of the study, the study tool was built.

- The official approvals were taken from the competent authorities to apply the study to the study community.

- Then the psychometric characteristics (Validity and Reliability) of the tool were verified. Then the tool was applied to the study sample, the information was entered into the computer memory and the study questions were answered. The following criterion was used to judge the items degrees:

$\checkmark \quad$ If the arithmetic mean of the item is less than or equal to (2.33) the item degree is low.

$\checkmark$ If the arithmetic mean of the item is restricted between (2.34-3.67), the degree of the item shall be intermediate.

$\checkmark \quad$ If the arithmetic mean of the item is greater than or equal to (3.68), the degree of the item shall be high.

- Extracting and discussing the results.

- Formulation of recommendations.

\subsection{Study Variables}

Independent variables are: First: the academic level which has two sub-levels (Associate Professor and above, Assistant Professor and below). Second: The faculty that has two levels (humanitarian, scientific).

The dependent variable is: the degree of symmetrical among faculty members at Tafila Technical University 


\subsection{Statistical Treatments}

To answer the first question in this study, the mean and standard deviations were used. In order to answer the second study question, multivariate analysis of variance (MANOVA) was used to identify the differences in the areas of the study tool by the variables of the study (faculty, academic level) and the (Two-Way ANOVA) to identify the differences significance in the total degree of the study tool by study variables (faculty, academic level).

\section{Results and Discussion}

The aim of this study was to know the degree of symmetrical among the faculty members at Tafila Technical University from their point of view. After all the procedures were done, whether related to the preparation of the study tool or the application. Data were processed and analyzed and the study came with the following results according to the questions:

\subsection{Results of the First Question}

To answer the question of the first study: "What is the degree of symmetrical among the faculty members at Tafila Technical University from their point of view? The means and standard deviations of the study tool areas and its items were used. Table (4) shows the values of the means and the standard deviations, the level and the degree of the study tool area.

Table 4. Means and Standard Deviations of the Degree of Symmetrical among Faculty Members at Tafila Technical University from Their Point of View

\begin{tabular}{lllll}
\hline Area & Mean & Standard Deviation & Level & Degree \\
\hline Membership & 3.26 & 1.05 & 1 & Medium \\
Similarity & 3.07 & 0.89 & 2 & Medium \\
Loyalty & 2.96 & 0.93 & 3 & Medium \\
The tool as a whole & 3.09 & 0.84 & - & Medium \\
\hline
\end{tabular}

Table (4) shows that the mean of the degree of symmetrical among faculty members at Tafila Technical University from their point of view reached (3.09) and with a standard deviation of (0.84). This degree is medium. All degrees came as medium. The area of membership ranked first with a mean of (3.26) and a standard deviation of (1.05). Similarity came in the second rank came with a mean of (3.07) and a standard deviation of (0.89). The last place was occupied by the loyalty area with a mean of (2.96) and a standard deviation of (0.93).

The following is a detailed presentation of the degree of symmetrical among the faculty members of Tafila Technical University from their point of view. They are as follows:

\section{Area of loyalty}

Means and standard deviations of loyalty area items were calculated. Table (5) shows these results.

Table 5. The Means and Standard Deviations of Loyalty Area Items

\begin{tabular}{llllll}
\hline $\begin{array}{l}\text { Item } \\
\text { No. }\end{array}$ & Item Content & Mean & $\begin{array}{l}\text { Standard } \\
\text { Deviation }\end{array}$ & Level & Degree \\
\hline 1 & Seriously care about the future of the university. & 3.12 & 1.33 & 1 & Medium \\
3 & I feel constant loyalty to university. & 3.04 & 1.14 & 2 & Medium \\
4 & $\quad \begin{array}{l}\text { Proud to be a faculty member in this university. } \\
5\end{array}$ & 3.02 & 1.19 & 3 & Medium \\
6 & $\begin{array}{l}\text { I defend the university and its policy before others } \\
\text { I think that the achievements of the university is a source } \\
\text { of pride for the members of the teaching staff }\end{array}$ & 3.01 & 1.17 & 4 & Medium \\
2 & $\begin{array}{l}\text { I got upset when others criticize the university in non } \\
\text { objective manner. }\end{array}$ & 2.82 & 1.22 & 5 & Medium \\
7 & $\begin{array}{l}\text { I like to speak in public about the successful projects } \\
\text { implemented by the University. }\end{array}$ & 2.81 & 1.22 & 7 & Medium \\
$1-7$ & $\quad 2.96$ & 0.93 & - & Medium \\
\hline
\end{tabular}


Table (5) shows that the mean of the field of loyalty was (2.96) and with a standard deviation of (0.93). This degree is medium, and all degrees of this dimension were medium. The first item, which stated that "Seriously care about the future of the university." ranked first with a mean of (3.12) and a standard deviation of (1.33). The third item came in the third place "I feel constant loyalty to university" with a mean of (3.04) and standard deviation of (1.14), the seventh item "I like to speak in public about the successful projects implemented by the University" came in the last place with a mean of (2.81) and a standard deviation of( 1.22).

\section{Area of similarity}

Means and standard deviations for the area of similarity were calculated and Table (6) shows these results.

Table 6. The Means and Standard Deviations of Similarity Area Items

\begin{tabular}{|c|c|c|c|c|c|}
\hline $\begin{array}{l}\text { Item } \\
\text { No. }\end{array}$ & Item Content & Mean & $\begin{array}{l}\text { Standard } \\
\text { Deviation }\end{array}$ & Level & Degree \\
\hline 8 & $\begin{array}{l}\text { I Make the maximum effort to achieve the } \\
\text { university goals. }\end{array}$ & 3.21 & 1.27 & 1 & Medium \\
\hline 13 & $\begin{array}{l}\text { I think that the image of the university in the } \\
\text { community is similar to my expectations. }\end{array}$ & 3.18 & 1.05 & 2 & Medium \\
\hline 6 & Work at the university to achieve its mission. & 3.09 & 1.15 & 3 & Medium \\
\hline 10 & $\begin{array}{l}\text { I try to make my decisions at work avoiding the } \\
\text { negative consequences that may affect the } \\
\text { university. }\end{array}$ & 3.00 & 1.10 & 4 & Medium \\
\hline 11 & See university problems as my personal problems. & 2.96 & 1.20 & 5 & Medium \\
\hline 12 & $\begin{array}{l}\text { I believe that my values and values of the university } \\
\text { are very similar. }\end{array}$ & 2.96 & 1.15 & 6 & Medium \\
\hline $8-13$ & The area as a whole " similarity" & 3.07 & 0.89 & - & Medium \\
\hline
\end{tabular}

Table (6) shows that the mean of the area of similarity is (3.07) with a standard deviation of (0.89). This degree is medium. All the items in this area came as medium. The eighth item, which states that "I make the maximum effort to achieve the university goals." Came in the first place with a mean of (3.21) and standard deviation of (1.27). In the second place came the thirteenth item, "I think that the image of the university in the community is similar to my expectations" with a mean of (3.18) and a standard deviation of (1.05). In the last place came the twelfth item. "I believe that my values and values of the university are very similar", with a mean of (3.07) and a specific deviation of (0.89).

\section{Area of membership}

Means and standard deviations for the area of membership were calculated and Table (7) shows these results.

Table 7. The Means and Standard Deviations of Membership Area Items

\begin{tabular}{llllll}
\hline $\begin{array}{l}\text { Item } \\
\text { No. }\end{array}$ & Item Content & Mean & $\begin{array}{l}\text { Standard } \\
\text { Deviation }\end{array}$ & Level & Degree \\
\hline 18 & $\begin{array}{l}\text { I believe that I have many positive attitudes shared with others } \\
\text { who work at the university }\end{array}$ & 3.40 & 1.21 & 1 & Medium \\
17 & I easily identify my identity through the university. & 3.32 & 1.26 & 2 & Medium \\
19 & For me, the university is a large family. & 3.30 & 1.27 & 3 & Medium \\
16 & I describe myself to others by saying" I work at the university, & 3.27 & 1.22 & 3 & Medium \\
& I'm from the university". & 3.21 & 1.31 & 5 & Medium \\
15 & I fee very happy because I work in this university. & 3.06 & 1.26 & 6 & Medium \\
14 & I belong to the university I work in. & 3.26 & 1.05 & - & Medium \\
$14-18$ & The area as a whole " membership" & & &
\end{tabular}


Table (7) shows that the mean of the area of membership in general is (3.26) with a standard deviation of (1.05). This degree is medium. All the items in this area came as medium. The eighth item, which states that "I believe that I have many positive attitudes shared with others who work at the university", came in the first place with a mean of (3.40) and standard deviation of (1.21). In the second place came the seventeenth item, "I easily identify my identity through the university" with a mean of (3.32) and a standard deviation of (1.26). In the last place came the fourteenth item. "I belong to the university I work in ", with a mean of (3.06) and a specific deviation of (1.26).

This may be attributed to the fact that symmetrical requires a professional intellectual culture in which the faculty member tends to see himself as representing the organization in his interactions with others. This requires a kind of harmony and compliance. It requires the university to adopt democratic and participatory manner in decision-making and meeting the needs of members, improving their conditions and granting them academic freedom. This study agrees with Al Shawawrah's (2015) study, which showed that the degree of symmetrical among the teachers was medium, and also agreed with the study by (al Qarala, 2005) that showed that the perceptions of the teaching staff members about the perceived participation came as medium and differed with the study of Al Saud, Sarayra, and Khalid (2009), which showed that the degree of symmetrical among faculty members in public universities was high.

\subsection{Results Related to the Second Question}

To answer the question of the second study: "Are there significant differences at the level of significance of $(0.05=\alpha)$ in the degree of symmetrical among faculty members at Tafila Technical University from their point of view attributed to the variables of the faculty and academic level ?" 2-WAY ANOVA was used to determine the significance of differences in the means of symmetrical by faculty and academic level variables. As the total degree of symmetrical is dependent variable and the variables of the faculty (scientific, humanitarian) and the academic level (associate professor and above, assistant professor and below) are independent variables. MANOVA has been used to identify the significance of differences in means in each area of symmetrical. As the areas (Loyalty, Similarity, Membership) are dependent variables, the variables of the faculty (scientific, humanitarian) and the academic level (Associate Professor and above, Assistant Professor and below are independent variables. Table (8) shows the values of the means and the standard deviations of the level of symmetrical by variables of faculty and academic level.

Table 8. Means and Standard Deviations of the total Degree and for Each Area of Symmetrical by Faculty and Academic Level Variables

\begin{tabular}{llllll}
\hline \multirow{2}{*}{ Area } & \multicolumn{2}{l}{ Academic Level } & \multicolumn{2}{l}{ Associate professor and above } & \multicolumn{2}{l}{ Assistant professor and below } \\
\cline { 2 - 6 } & Faculty & Scientific & Humanitarian & Scientific & Humanitarian \\
\hline Loyalty & Mean & 2.66 & 3.71 & 2.96 & 2.75 \\
& Standard Deviation & 0.56 & 0.64 & 1.05 & 0.82 \\
Similarity & Mean & 2.83 & 3.78 & 3.08 & 2.82 \\
& Standard Deviation & 0.78 & 0.71 & 0.95 & 0.71 \\
Membership & Mean & 3.48 & 3.77 & 3.12 & 3.09 \\
& Standard Deviation & 0.90 & 1.07 & 1.08 & 1.02 \\
Total Degree & Mean & 2.99 & 3.76 & 3.06 & 2.88 \\
& Standard Deviation & 0.59 & 0.66 & 0.94 & 0.72 \\
\hline
\end{tabular}

Table (8) shows that the highest mean of the total degree of symmetrical among faculty members at Tafila Technical University from their point of view was the level of associate professor and above in the humanitarian faculties, where it reached (3.76) with standard deviation of (0.66). The lowest from the pony of view of the faculty members was the level of assistant professor and below and from the humanitarian faculties, where they reached a mean of (2.88) and a standard deviation of (0.72). It is also noted that the faculty members of associate professor and above in the humanities faculties have obtained the highest means in the three areas (loyalty, similarity, membership), where the means reached $(3.71,3.78,3.77)$ respectively and standard deviations $(0.64,0.71,1.07)$ respectively. The following table shows the means and the standard deviations of the level of symmetrical by the academic level variable. 
Table 9. Means and Standard Deviations of the Total Degree and for Each of the Areas of Symmetrical According to the Academic Level Variable

\begin{tabular}{llll}
\hline Area & & Associate professor and above & Assistant professor and below \\
\hline Loyalty & Mean & 3.11 & 2.89 \\
& Standard Deviation & 0.79 & 0.98 \\
Similarity & Mean & 3.24 & 2.99 \\
& Standard Deviation & 0.89 & 0.88 \\
Membership & Mean & 3.61 & 3.11 \\
& Standard Deviation & 0.97 & 1.05 \\
Total Degree & Mean & 3.32 & 3.00 \\
& Standard Deviation & 0.72 & 0.877 \\
\hline
\end{tabular}

Table (9) shows that means of symmetrical in general and for each area was higher for faculty members at the level of associate professor and above. Where the total degree reached (3.32) with standard deviation of (0.72). To detect the source of differences in means in the total degree of symmetrical, the 2-Way ANOVA was used and Table (10) shows these results.

Table 10. Two - Way Analysis of Variance with Respect to Difference in the Means of the Total Degree in the Symmetrical by the Variables of the Academic Level and the Faculty

\begin{tabular}{|c|c|c|c|c|c|}
\hline Source of Variance & Total of Squares & $\begin{array}{l}\text { Degree of } \\
\text { Freedom }\end{array}$ & $\begin{array}{l}\text { Squares } \\
\text { Average }\end{array}$ & $\begin{array}{l}\text { (F) } \\
\text { Value }\end{array}$ & $\begin{array}{l}\text { Significanc } \\
\text { e Level }\end{array}$ \\
\hline Academic Level & 4.017 & 1 & 4.017 & 6.071 & $* 0.015$ \\
\hline Faculty & 2.168 & 1 & 2.168 & 3.277 & 0.073 \\
\hline Academic Level * Faculty & 5.402 & 1 & 5.402 & 8.164 & $* 0.005$ \\
\hline Error & 80.059 & 121 & 0.662 & & \\
\hline Total & 1286.523 & 125 & & & \\
\hline Corrected Error & 88.617 & 124 & & & \\
\hline
\end{tabular}

Table (10) shows statistically significant differences in the total degree of symmetrical among the faculty members of Tafila Technical University from their point of view due to the academic level variable where the value of (F) of the university variable was (6.071), it is statically significant at the level of $(\alpha=0.05)$. The differences were in favor of the level of associate professor and above, with a mean of (3.32) and a standard deviation of (0.72). The results also showed statistically significant differences in the total degree of symmetrical attributed to the interaction between the academic and faculty variables, where the value of (F) was (8.164), it is statically significant at the level of $(\alpha=0.05)$. The differences were in favor of the level of associate professor and above in the humanitarian faculties, where the mean reached (3.76) with standard deviation of (0.66). There were no statistically significant differences in the total degree of symmetrical degree the faculty members of Tafila Technical University from their point of view attributed to the faculty variable, where the value of (F) was (3.277), which is not statistically significant at the level of significance $(\alpha=0.05)$.

To determine whether there were statistically significant differences in each of the areas of symmetrical (loyalty, similarity, membership), the MANOVA analysis was used and Table 11 shows these results.

Table 11. Results of the Analysis of the Multiple Variance of the Mean of the Total Performance of the Sample Members by Academic Level and Faculty Variables

\begin{tabular}{|c|c|c|c|c|c|}
\hline The Variable & Test & Test Value & (F) Value & $\begin{array}{l}\text { Degree } \\
\text { Freedom }\end{array}$ & $\begin{array}{l}\text { Significance } \\
\text { Level }\end{array}$ \\
\hline Academic Level & Hottelling & 0.055 & 2.17 & 3 & 0.95 \\
\hline Faculty & Hottelling & 0.062 & 0.247 & 3 & 0.065 \\
\hline $\begin{array}{l}\text { Academic Level * } \\
\text { Faculty }\end{array}$ & Wilks Lambda & 0.851 & 6.93 & 3 & $* 0.000$ \\
\hline
\end{tabular}

* Statistically significant at $(\alpha=0.05)$ 
Table (11) shows not having any statistically significant differences in the areas of symmetrical (loyalty, similarity, membership) attributed to the academic level variable. The value of the Hottelling test was $(0.055)$ and the value of $(F)=2.17$, not statistically significant at the significance level $(\alpha=0.05)$, or for the faculty variable where the value of the Hottelling test was $(0.062)$ and the value of $(F)=(0.247)$, not statistically significant at the $(\alpha=0.05)$ level. The results also showed statistically significant differences in the areas of symmetrical attributed to the interaction between the academic and faculty variables, where the value of the Wilks Lambda test reached $(0.851)$ with $(\mathrm{F})$ value (6.93), which is statistically significant at the significance level $(\alpha=0.05)$. To determine in which areas the differences were statistically significant, the variance analysis was conducted and Table (12) shows these results.

Table 12. Results of Variance Analysis of the Differences between the Average Performance of the Sample Members on the Areas of Symmetrical by the Interaction of the Variables of the Academic Kevel and Faculty

\begin{tabular}{|c|c|c|c|c|c|c|c|}
\hline $\begin{array}{l}\text { Dependent } \\
\text { Variable }\end{array}$ & $\begin{array}{l}\text { Total } \\
\text { Squares }\end{array}$ & of & $\begin{array}{l}\text { Degree } \\
\text { Freedom }\end{array}$ & of & $\begin{array}{l}\text { Squares } \\
\text { Average }\end{array}$ & (F) Value & $\begin{array}{l}\text { Significance } \\
\text { Level }\end{array}$ \\
\hline Loyalty & 9.935 & & 1 & & 9.935 & 12.55 & $* 0.001$ \\
\hline Similarity & 9.206 & & 1 & & 9.206 & 12.74 & $* 0.001$ \\
\hline Membership & 0.619 & & 1 & & 0.619 & 0.570 & 0.452 \\
\hline
\end{tabular}

* Statistically significant at $(\alpha=0.05)$

The table shows statistically significant differences in the areas of loyalty and similarity attributed to the interaction of the academic level and the faculty variables, where (F) values reached (12.55) and (12.74) respectively. These values are statistically significant at the significance level of $(\alpha=0.05)$. Such differences came in favor of the faculty members at the level of associate professor and above in the humanitarian faculties, where they obtained the highest means as shown in Table (9). The results also showed not having statistical significant differences in membership due to the interaction of the academic level and faculty, where the value of (F) reached (0.570), which is not statistically significant at the significance level $(\alpha=0.05)$. This result may reflect the nature of the relationship between the faculty members in the humanitarian faculties, which is mostly positive and warm in the work place, due to the nature of disciplines in the humanitarian faculties that emphasize these values and compliance and enlighten the students and refine their skills. These results emphasize the maturity and experience of the members of the faculty at the level of associate professor and above, which made them more compatible with their university, and this result is an indication of the extent of harmony among the members of the faculty and the strong relation between symmetrical and the social aspects of the organization.

This study agreed with the study of Rachid (2003) which showed that the level of identification of the individual increase by the number of years of experience and agreed with the study of Al Saud, Sarayra, and Khalid (2009), which showed that the degree of symmetrical among faculty members was high, and also agreed with Cremer's (2005) study, which showed that interaction between procedural and distributional justice was only among workers who have a sense of symmetrical, and agreed with the study of Al Shammari (2012), which showed a degree of symmetrical at Kuwait University.

\section{Recommendations}

- Engage faculty members in the decision-making process, which makes them feel important and responsible for the success and implementation of programs, events and university activities.

- The university should conduct periodic surveys to identify and realize the wishes and needs of faculty members.

- Give the issue of symmetrical the importance in the periodic meetings of faculty members at the university through seminars and programs.

- Conduct more studies on symmetrical and link them to some variables (leadership, job satisfaction, symmetrical loyalty).

\section{References}

Al Bashabshah, S. (2006). The impact of symmetrical justice on the formation of symmetrical in Jordanian public institutions. Jordanian Journal of Labor Administration, 4. 
Al Hathlol, S. (2008). Symmetrical loyalty and its impact on the level of job performance. Unpublished Master Thesis, Naif Arab University for Security Sciences. Riyadh, Saudi Arabia.

Al Qarala, A. (2005). The impact of perceived and desirable participation in the crystallization of symmetrical among the members of the teaching staff in the public Jordanian universities. Unpublished Master Thesis, Mu'tah University, Jordan.

Al Qarala, A. (2011). The impact of perceived and desirable participation in the crystallization of symmetrical from the point of view of the members of the teaching staff in the public Jordanian universities. Unpublished Master Thesis, Mu'tah University, Jordan.

Al Saud, Sarayra, R., \& Khalid, A. (2009). Symmetrical of faculty members in the public Jordanian universities and its relation to their job performance. Journal of Jordanian University Studies, Amman, Jordan.

Al Shammari, A. (2012). The degree of practicing leadership roles among the deans of the faculties of Kuwait University and its relation to the symmetrical among the members of the teaching staff from their point of view. Unpublished Master Thesis, Faculty of Educational Sciences, Middle East University, Jordan.

Al Shawawrah, T. (2015). The effect of symmetrical on work motivation among teachers of the Jordanian Ministry of Education in Directorate of Education of Karka Borough. Journal of the Islamic University for Economic and Administrative Studies, 24(1), 120-141.

Chan, S. (2006). Symmetrical and commitment of human development. Torganization Journal of Management Development, 25(1), 249-268.

Cremer, D. (2005). Procedural and distributive justice effects moderated by symmetrical. Journal of Managerial Psychology, 20(3), 4-13. https://doi.org/10.1108/02683940510571603

Hant, S., \& Morgan, R. (1994). Symmetrical commitment: One of many commitments or K mediating construct. Academy of Management Journal, 37(6), 1568-1597. https://doi.org/10.2307/256799

Jeffry, T. (2002). Explaining the varying effects of symmetrical on cooperation: the moderating role of subgroup reputations. Working Papers, Harvard Business School, Morgan Hal, 333.

Johnson, W., Johnon, A., \& Heimberg, F. (1999). A primary and second - order component analysis of the symmetrical questionnaire. Educational and Psychological Measurement, 59(1), 159-170. https://doi.org/10.1177/0013164499591011

Knippenberg, \& Schie. (2000). Foci and correlates of symmetrical. Journal of Occupational and Symmetrical Psychology, 73, 137-147. https://doi.org/10.1348/096317900166949

Lozi, M. (2006). Symmetrical development: Its basics and modern concepts. Amman: Dar Wael.

Mael, F., \& Ashforth. (2001). Identification in work, war, sport and religion: Contrasting the benefits and risks. The Executive Management: Committee. England.

Nadler, \& Tushman, (1980). Managing organizations readings and cases. Little, Brown and Company Boston: Toronto.

Rachid, M. (2003). Symmetrical identity and symmetrical: An analysis of the concept and behavioral dimensions of its applications. Research Center, Faculty of Administrative Sciences, King Saud University, Saudi Arabia.

Sarayra, K. (2005). The symmetrical among the faculty members at public Jordanian universities and its relation to their sense of security and job performance. Uunpublished Doctoral Thesis, Amman Arab University for Graduate Studies, Amman, Jordan. 